On putting $y=0$ we deduce that

$$
1+\frac{1}{3^{2}}+\frac{1}{5^{2}}+\frac{1}{7^{2}}+\cdots=\frac{\pi^{2}}{8}
$$

from which it is an easy exercise to deduce that

$$
1+\frac{1}{2^{2}}+\frac{1}{3^{2}}+\frac{1}{4^{2}}+\cdots=\frac{\pi^{2}}{6} \text {. }
$$

As in the case of differentiation, this is merely the first step of many similar possible deductions.

FRANK CHORLTON

Department of Mathematics, University of Aston, Birmingham B4 7ET

\title{
Obituary
}

\section{Winifred and Theodore Combridge}

That this appreciation of Winifred and Theodore Combridge is relatively brief is in no way a measure of the affection in which they were held by many of the more senior members of the Mathematical Association, and certainly not of the enormous service that they rendered over many years for the benefit of all members, young and old, past, present and future.

Inevitably, as years pass, there will be an increasing proportion of the Association's membership who will not have been in touch with Mr and Mrs Combridge and their contemporaries.

Even a selective catalogue of their contributions to the growth and prestige of the Association, however, will demonstrate how much their successors owe to their performance and example.

The history of the Mathematical Association, from its very beginnings in the eighteen-seventies, is one of progress, innovation and dedication to the improvement of mathematical education. The quarter of a century following the second world war was undoubtedly one of the most critical and most fruitful periods of that history.

It was then that Winifred Adelaide Cooke and John Theodore Combridge were among the prime movers. She, a teacher of great distinction, had joined the Association in 1934. From 1952 to 1962 she was Honorary Secretary and only those most closely involved with the administration of the M.A. could realise how much time, effort and expertise she gave to that post. Later, however, her zeal and energy had another outlet when she served as Secretary of the Centenary Appeal.

To mark the 1971 Anniversary the M.A. had boldly resolved to acquire a permanent headquarters. To fund this, an estimated $£ 30000$ was required. 
This figure today seems astonishingly modest but on 1971 prices meant that a substantial house could be acquired, converted and appropriately fitted. That the total was reached and the mission accomplished represented a great achievement. The credit for the success of the appeal could be widely attributed, but the contribution of Miss Cooke cannot be over-estimated. Nor can the pleasure shared by many members when at the 1972 Annual General Meeting in Edinburgh the engagement of Winifred and Theodore was announced and special tributes were paid to them for their services to the Association. Very shortly afterwards they were married, to enjoy a happy life together until illness in 1986 brought their deaths, hers in October and his in December.

Meanwhile their interest in the M.A. continued unabated, and if attendance at meetings diminished, their help to committees, branches and individual members remained constantly available. They were, of course, vice-presidents and members of Council throughout.

Any list of $\mathrm{Mr}$ Combridge's offices can be only representative, not complete. After holding other posts in King's College, London, he became Registrar in 1947. A member of the M.A. since 1930, he was Chairman of the Teaching Committee from 1950 to 1956, President 1961/2, and for some years afterwards Chairman of the Standing Committee of Council. But also he was instrumental in the formation of the Joint Mathematical Council, and from 1964 until a professional team was appointed he undertook a major part of the administration of the Institute of Mathematics and its Applications.

To cite only a few other activities, there was the work of the Schools and Industry Committee of the Association, forward-looking and seminal, and led so effectly by J.T.C. A splendid conspectus Count me in edited by him, grasped the problems of numeracy, or the lack of it, and a history of the M.A. owes much to his spadework. He had also, while at King's College, compiled a Bibliography of relativity and gravitation theory (he had been a student of Eddington at Cambridge) in a form that typified his thorough attention to detail.

Indeed, in the great number of communications sent to me since it was announced that I was compiling this memoir, the words meticulous, integrity and respect recur. $\mathrm{Mr}$ and Mrs Combridge were, individually and together, splendid company. They were a source of inspiration in many quarters, and their advice and guidance will be long remembered and appreciated, so will their powers of leadership, and their skill in the conduct of meetings.

Perhaps I may be forgiven one personal paragraph. In my presidential address to the M.A. in $1967 \mathrm{I}$ had acknowledged the influence of three of my predecessors. One was $\mathrm{Mr}$ Combridge, "whose sterling character and devotion to duty have been an example to us all and a considerable influence on me. It was always a pleasure to go into the Registrar's Office at King's College and see the mass of paper work so tidily docketed and precisely organised. Indeed precision is one of the qualities which I associate with $\mathrm{Mr}$ Combridge; so are an effectiveness in speech and writing, a steadfastness in 
friendship and adversity, and a happy wit which has enlivened many a meeting". I know that this summarises, however, inadequately, much that is felt by so many members who have been fortunate to have worked with him.

The Association has long held, with Bacon, that every man is "a debtor to his profession". But mathematics, teachers of mathematics, and a host of associated facets, are in fact in debt to Winifred and Theodore Combridge. We honour their memory.

FRANCIS KELLAWAY

Byways, 14 Knowle Road, Budleigh Salterton, Devon EX9 6AR

\section{Problem corner}

Solutions are invited to the following problems. They should be addressed to Graham Hoare at Dr Challoner's Grammar School, Chesham Road, Amersham, Bucks HP6 5HA, and arrive not later than February 10 please.

71.G (Dmitry P. Mavlo, Moscow) Triangle $D E F$, area $S$, is inscribed in an arbitrary triangle $A B C$. Prove that the areas $S_{i}(i=1,2,3)$ of the other triangles formed, satisfy

$$
S \geqslant \frac{3}{\frac{1}{S_{1}}+\frac{1}{S_{2}}+\frac{1}{S_{3}}},
$$

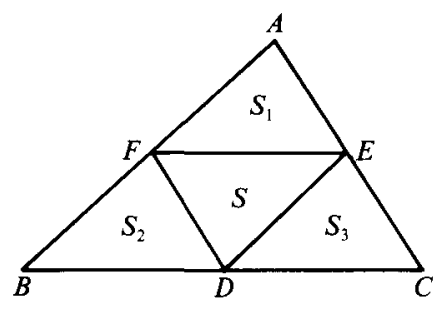

equality holding if and only if $D, E, F$ are the mid-points of the sides of the triangle $A B C$.

71.H (C. M. Jones, Dunedin, N.Z.) To find a perfect cube which is not a multiple of 10 , such that if the right hand digit is removed the integer becomes a perfect square, requires an integral solution of a diophantine of the form

$$
x^{3}-y=10 z^{2}, \quad 1 \leqslant y \leqslant 9 .
$$

Are there any solutions of this equation? More generally, is the equation $x^{3}-y=k z^{2}$ soluble for any value of $k$ and $y$, a non-zero constant?

\section{Solutions and comments on 71.C and 71.D (June 1987)}

71.C The tangent at a point $P$ on a circle with centre $O$ meets a line $d$ through $O$ (but not through $P$ ) at $A$. The point $B$ on $d$ is such that $O B=O A$. Any secant through $B$ cuts the circle at $X$ and $Y$; and $P X, P Y$ cut $d$ at $U, V$ respectively. Prove (preferably by elementary Euclidean geometry) that $O U=O V$. 